\title{
Leadership Styles and Employee Performance in Cameroon: The Case of St. Veronica Medical Centre
}

\author{
Francisca Hongla Biaka \\ School of Management Sciences, Biaka University Institute of Buea, Buea, Cameroon \\ Email: franka_biaka@yahoo.co.uk
}

How to cite this paper: Biaka, F. H. (2020). Leadership Styles and Employee Performance in Cameroon: The Case of St. Veronica Medical Centre. Open Journal of Leadership, 9, 179-197.

https://doi.org/10.4236/oj1.2020.94011

Received: November 4, 2020

Accepted: November 29, 2020

Published: December 2, 2020

Copyright (๑) 2020 by author(s) and Scientific Research Publishing Inc. This work is licensed under the Creative Commons Attribution International License (CC BY 4.0).

http://creativecommons.org/licenses/by/4.0/

\section{(c) (i) Open Access}

\begin{abstract}
This study investigated the role of leadership styles on employee performance in Cameroon. It was anchored on the premise that leaders exhibit a series of leadership behaviours with remarkable influence on the output of employees. Specifically, the study identified the leadership behaviours exhibited by managers in St. Veronica Medical Centre in enhancing employee performance and the specific behaviours that affect the performance of these employees. Methodologically, the study employed a quantitative approach which benefited from a descriptive survey design. Data were gleaned from the administration of questionnaires to 100 personnel in St. Veronica Medical Centre via simple random sampling. The data were analyzed using SPSS 26 statistical package. From the regression analysis, this study found that democratic, transformational and ethical leadership styles had a significant positive effect on performance at $95 \%$ confidence level. Democratic and transformational leadership styles were the most predominantly used styles and did not differ significantly with respect to sex. Authoritative leadership had the least impact on performance proven by its insignificant and negative beta coefficient. The conclusions of this study commend the management of St. Veronica Medical Centre for the use of transformational and ethical leadership styles which help build trust, inspire shared vision and encourage creativity. Hence it was recommended that leaders of this institution should pay more attention to developing efficient team work and express warm concern and trust to co-workers through transformational leadership behavior. Nevertheless, other leadership styles could be implemented occasionally for better performance.
\end{abstract}

\section{Keywords}

Leadership Styles, Transformational Leadership, Ethical Leadership, Employee Performance 


\section{Introduction}

The role of leaders in today's organizations has changed and the success of any organization relies on the leadership styles practiced by the leaders. Mintzberg (2010) propounded that true leaders engage others with their consideration and modesty because they involve themselves in what they are actually doing not for individual gains. For the success of an organization to be secured, its labour force needs to be inspired to invest themselves in the organisation's mission: effectiveness can be procured if staffs are stimulated as such effective organizations require effective leadership (Wall, Solum, \& Sobol, 1992) cited in Suri (2016).

Fiedler and House (1988) indicated that organisational performance will suffer in direct proportion to the neglect of this effective leadership. Ultimately it is the individual employee who either performs, or fails to perform, a task. In order for an organisation to perform, an individual must set aside his personal goals, at least in part, to strive for the collective goals of the organisation (Cummings \& Schwab, 1973).

Within the context of an organisational, the outcome of performance is determined by the organisation itself (Cummings \& Schwab, 1973). At the core of organizational success are the employees because of the paramount role they play. Thus, effective leadership enables greater participation of the entire workforce, and can also influence both individual and organisational performance (Bass, 1997; Mullins, 1999). When leaders initiate and pursue effectiveness, it facilitates the attainment of the follower's desires, which then results in effective performance and overall organizational success (Fiedler \& House, 1988; Maritz, 1995; Ristow et al., 1999).

Outstanding leaders, in terms of effectiveness, are perceived to show a strong and direct, but democratic and participative leadership style, and are seen as agents of change and visionaries who increase organisational performance (Swanepoel et al., 2000). Maccoby (2000) indicated that the need of firms to flourish in the world of escalating competitiveness, of technological advances, of altering government regulations and of changing employee attitudes, requires an advanced level of leadership more than ever before. His views further demonstrate the importance of leadership in the business arena.

Bass (1997) posited that in the modern business environment much research has proven that leaders make a difference in their subordinates' performance, and also make a difference as to whether their organisations succeed or fail. Kotter (1988) on his part argued for the ever-increasing importance of leadership in organisations, because of significant shifts in the business environments, such as the change in competitive intensity and the need for more participation of the total workforce.

On the other hand, employee performance is also an important building block of an organization and factors which lay the foundation for high performance must be analyzed by the organizations. Since every organization cannot progress by depending on one or two individual effort, it is the collective effort of all the 
members of the organization. As such, performance is viewed as a major multi-dimensional concept aimed to achieve results and is highly correlated to the strategic goals of an organization (Mwita, 2000).

However, leadership exercises a pivotal role with an influential magnitude on employee performance across diverse organizations (Ogbonna \& Harris, 2000). The impact of multiple leadership styles on employee performance therefore remains a bone of contention across empirical debates among researchers and scholar alike (Gadot, 2006). Arguments culled from empirical science attest that the output of employees ascends when piloted by extraverted leaders in scenarios of employee passiveness but descends when they are proactive (Grant, Christian, \& Price, 2007). Wang et al. (2005) already found that leadership has an immense influence on the performance of employees.

Therefore, there is an urgent need for revitalization of leadership styles across organization in Cameroon in general and St. Veronica Medical Center to be specific so as to enhance employee performance in the midst of continual rising challenges due to scandals and unethical behaviors not just from employees but unfortunately from leaders. Dorasamy (2010) asserted that the credibility of institutions is at risk of erosion in the absence of adherence to acceptable standards by the leadership of organizations. This is in tandem with Judge \& Piccolo (2004) who found that such disregard is rooted in outright denial by leaders to subject themselves to ethical justification.

On the heels of the status quo is an unfortunate insufficiency of literature to foster a full comprehension of the outcome of leadership patterns on employee performance (Kalshoven et al., 2011) though some researchers (Brown et al., 2005) have attempted to explore the concept of ethical leadership and its impact on employee conduct. Generally, it seems empirical studies in management largely ignore leadership and yet employee performance is greatly affected by either the ethical or unethical behaviors of those who lead them.

\subsection{Statement of the Problem and Justification of the Study}

One central tenet of this paper is the perceived expectation of a manager or leader to exhibit a right behaviour towards employees or subordinates. Yet in most organizations in Cameroon, it seems that work schedules are task-focused and routine, with no flexibility while decisions and policies are imposed on subordinates. This paper observed that in such organizations where the leadership perceives employees as mere hands to get the job done, employees would do well due to the standards and measure being assigned to them.

For employees to accomplish their work, managers must encourage individuals who report to them, co-workers, and supervisors or customers. For effective and efficient organizational leadership, the human factor must be critically looked into so as to enhance their productivity. St. Veronica Medical Centre has a set of leadership standards expected to be exhibited by its managers or leaders with the view to improving employee performance. 
Similarly, research has been carried out on related topics but this paper perceives the existence of a relationship gap between leadership and organizational performance. Leadership has mostly been studied using an organizational perspective focused on strategy and organizational performance. Given its salience in organizational environment, however, leadership may also have internal as well as external consequences. Yet, the potential impact of leadership on internal human resource aspects has received only minimal interest from researchers. This research hopes to find data that will explore the impact of leadership on employee performance especially in the context of Cameroon.

The problem for this study therefore is to establish the leadership styles that are exhibited at St. Veronica Medical Centre and to ascertain how they affect the performance of employees. The status quo is fostered by the insufficiency of empirical data on the topic in Cameroon in general and St. Veronica specifically, a situation which inhibits a proper understanding of the subject as much as its implementation.

\subsection{Research Objective}

- To determine the leadership style which is predominantly used by managers of SVMC and its effect on employees' performance;

- To examine if gender determine managerial leadership styles in SVMC;

- To develop a linear regression model which show the relationship among leadership styles and employee performance.

\subsection{Specific Research Questions}

- What leadership style is predominantly used by managers of SVMC and how does it affect employees' performance?

- To what extent does gender determine managerial leadership styles in SVMC?

- How can a linear regression model be developed to show the relationship among different leadership styles and employee performance?

\subsection{Research Hypothesis}

The hypotheses were tested at the 0.05 level of significance using multiple linear regression to determine how much the criterion variable has been explained by the predictors as well standardized beta weights to determine the relative contribution of the predictors to the criterion. Also, an independent sample t test was used to examine the variation of leadership style in terms of gender at SVMC.

$\mathrm{Ho}_{1}$ : The leadership style predominantly used by managers of SVMC has no significant effect on employees' performance.

$\mathrm{Ho}_{2}$ : There is no significant difference between gender and leadership styles in SVMC.

$\mathrm{Ho}_{3}$ : There is no significant relationship between the estimates of the linear regression model on leadership styles and employee performance. 


\section{Literature Review}

According to Armstrong (2004) leadership is simply the ability to persuade others willingly to behave differently for achieving the task set for them with the help of the group. Northouse (2010) sees it as a process whereby an individual influences a group of individuals to achieve a common goal. According to Northouse (2016) leadership is a process through which an individual influence a group of people to attain common goals. Contemporary, leaders do not rely upon their legitimate power to persuade individuals to do as they are told but they take an interest in an interaction with their subordinates or they raise and widen the interest of their subordinates (Northouse, 2016).

Leadership is the process by which a person exerts influence over people and inspires, motivates, and directs their activities to help achieve groups or organizational goals (Jones \& George, 2004). Therefore leadership is the ability to influence a group towards the achievement of its goals.

Empirical evidence attributable to (Burns, 1978; Bass, 1985) reports that transformational and transactional leadership approaches are the most important, widely used and tested for leadership studies. Similarly, Kodish (2006) argued that for leaders to demonstrate high quality, they must be strong enough in their ethical behaviors. In the paragraphs that ensue, these leadership styles:

\subsection{Transformational Leadership}

As propounded by Burns (1978) transformational leadership is a situation where leaders encourage their subordinates to increase the level of their beliefs, morals, perceptions, motivations and coalitions with the organization's objectives. Transformational leadership is such an engaging and inspiring relationship between the leaders and subordinates that enables subordinates to seriously examine the current assumptions and inspire them to think across new directions (Krishnan, 2012) and causes subordinates to give their appreciation, loyalty, obedience and trust to their leaders and to assign tasks without any questioning (Yukl, 2006). Transformational leaders show confidence and respect in their subordinates and have the ability to influence their subordinate's behavior in such a way that results in more work fulfillment and positive organizational outcomes (Givens, 2008). They help their subordinates to be productive, innovative and creative and adaptable to the various environmental conditions within the organization (Furkan, Kara, Tascan, \& Avsalli, 2010) and try to prevent the chances of work related problems (Berson \& Avolio, 2004).

\subsection{Ethical Leadership}

Oates and Dalmau (2013) expounds that ethical leadership is about doing what is right for the long term benefits of all stakeholders. They continue to say that ethical leadership is about balancing the organization's short term goals and longer term aspirations in a way that achieve positive results for all those who 
could be affected by the organization and the decisions of its leaders. Brown et al. (2005) suggested that the combination of integrity, ethical standards, and fair treatment of employees are the cornerstones of ethical leadership.

They defined ethical leadership as the demonstration of normatively appropriate conduct through personal actions and interpersonal relationships, and the promotion of such conduct to followers through two-way communication, reinforcement, and decision making. This definition implies that a leader should be both a moral person and a moral manager. It further shows that while demonstrating moral management behaviour, ethical leaders do not compromise ethical standards in pursuit of short term, bottom-line, organizational performance.

Treviño and Brown (2004) proposed that ethical leadership, in its true sense, promotes ethical conduct by practicing as well as managing ethics and holding. According to Mwita (2000), employee performance is the key multi character factor intended to attain outcomes which has a major connection with planned objectives of the organization. Studies have shown that employee performance can be increased if they are led by ethical leaders (Bello, 2012).

A study by Detert et al. (2000) revealed that an efficient leadership helps employees in discovering and polishing their contributions to the success of the organization. The study shows that effective leadership is more likely to lead to increase in employee performance. Brown and Treviño (2006) found that ethical leadership emphasizes fair treatment, shared values and integrity in common personnel and business transactions. They add that ethical leaders inspire favorable behaviors among employees, encourage high levels of pride and commitment to the organization, and shape the way employees perceive the work content.

Mayer et al. (2009) found positive effects of executive ethical leadership cascade to lower level employees through the ethical leadership practiced by supervisors. In their study, Brown et al. (2005) show that ethical leadership positively influences many important employee outcomes. Piccolo et al. (2010) found a positive relationship between ethical leadership and employee effort. Walumbwa and Schaubroeck (2009) found that perceptions of ethical leadership were related to increased employee voice via their influences on heightened psychological safety. Results of these studies show that ethical leadership favorably influence a significant number of employee outcomes. However, empirical studies on the effects of ethical leadership on employee performance are scanty.

\subsection{Democratic Leadership}

Lewin's study found that participative leadership, also known as democratic leadership, is typically the most effective leadership style. Democratic leaders offer guidance to group members, but they also participate in the group and allow input from other group members. In Lewin's study, children in this group were less productive than the members of the authoritarian group, but their contributions were of a higher quality. 
Participative leaders encourage group members to participate but retain the final say in the decision-making process. Group members feel engaged in the process and are more motivated and creative. Democratic leaders tend to make followers feel like they are an important part of the team, which helps foster commitment to the goals of the group. Using this style the leader would characteristically lay the problem before his or her subordinates and invite discussion. The leader's role is that of conference leader, or chair, rather than that of decision taker. He or she will allow the decision to emerge out of the process of group discussion, instead of imposing it on the group as boss (the Joining style).

\subsection{Authoritative Leadership Style}

Autocratic leadership, also known as authoritative leadership, is a leadership style characterized by individual control over all decisions and little input from group members. Autocratic leaders typically make choices based on their ideas and judgments and rarely accept advice from followers. Autocratic leadership involves absolute, authoritarian control over a group.

Authoritarian leaders provide clear expectations for what needs to be done, when it should be done, and how it should be done. This style of leadership is strongly focused on both commands by the leader and control of the followers. There is also a clear division between the leader and the members. Authoritarian leaders make decisions independently with little or no input from the rest of the group. Researchers found that decision-making was less creative under authoritative leadership. Lewin also concluded that it is harder to move from an authoritative style to a democratic style than vice versa.

Abuse of this method is usually viewed as controlling, bossy, and dictatorial. Authoritative leadership is best applied to situations where there is little time for group decision-making or where the leader is the most knowledgeable member of the group. The autocratic approach can be a good thing when the situation calls for rapid decisions and decisive actions. However, it tends to create dysfunctional and even hostile environments, often pitting followers against the domineering leader.

\subsection{Employee Performance}

As the performance of an organisation is dependent on the quality of the workforce at all levels of the organisation (Temple, 2002), it is essential to discuss the concept of individual performance. To them employee performance in effect reflects the efficiency of the organisation. People are an organisation's greatest assets: individuals and organisations have learned about the importance of the role of people in an organisation, and how the success of an organisation depends on its people (Bartlett \& Ghoshal, 1995).

The role of human resources is absolutely critical in raising performance in an organisation (Armstrong \& Baron, 1998). Ultimately it is the performance of many individuals, which culminates in the performance of an organisation, or 
the achievement of goals in an organisational context (Armstrong \& Baron, 1998). Amos et al. (2004) state that "the effective management of individual performance is critical to the execution of strategy and the organisation achieving its strategic objectives". Performance cannot be left in anticipation that it will develop naturally, despite the employee's natural desire to perform and be rewarded for it. This desire needs to be accommodated, facilitated and cultivated (Amos et al., 2004).

\subsection{Theoretical Underpinnings}

McGregor (1960), a behavioural psychologist, proposed that leadership strategies are influenced by a leader's assumptions about human nature. As a result of his experience as a consultant, McGregor summarized two contrasting sets of assumptions made by managers in industry. He developed two attitude profiles, or assumptions, about the basic nature of people. These attitudes were termed Theory $\mathrm{X}$ and Theory $\mathrm{Y}$.

It can therefore be seen that a leader holding Theory $\mathrm{X}$ assumptions would prefer an autocratic style, whereas one holding Theory $\mathrm{Y}$ assumptions would prefer a more participative style. The real value of McGregor's work was to the idea that a leader's attitude towards human nature has a large influence on how that person behaves as leader. Thus the relationship between a leader's expectation and the resulting performance of a subordinate has received much attention (McGregor, 1960). Generally, it has been found that if a manager's expectations are high, productivity is likely to be poor.

Some elements of Cameroonian culture provide a fertile ground for the practice by a Theory $\mathrm{X}$ leadership behaviour. These elements include overriding respect for elders, authoritarian political culture and high predisposition towards respect for authority. Moreover, certain negative attitudes prevalent among $\mathrm{Ca}$ meroonian workers demand Theory $\mathrm{X}$ behaviour if the manager expects to achieve results. Examples of such negative attitudes as identified by Wood include the abuse of office for private gain, fence sitting, laziness and lethargy; lack of commitment to work and poor time culture.

\section{Fiedler's Contingency Theory}

Fiedler was the first to develop this leadership theory, which shows that situational variable interacts with a leader's personality and behaviour. Fiedler (1967) believes that there is no single best way for managers to lead. Situations will create different leadership style requirements for a manager. The solution to a managerial situation is contingent on the factors that impinge on the situation. For example, in a highly routine (mechanistic) environment where repetitive tasks are the norm, a relatively directive leadership style may result in the best performance. However, in a dynamic environment a more flexible, participative style may be required. Fiedler looked at three situations that could define the condition of a managerial task:

- Leader member relations: How well do the manager and the employees get 
along?

- Task structure: Is the job highly structured, fairly unstructured, or somewhere in between?

- Position power: How much authority does the manager possess?

Another aspect of the contingency model theory is that the leader-member relations, task structure, and position power dictate a leader's situational control. Leader-member relations are the amount of loyalty, dependability, and support that the leader receives from employees. It is a measure of how the manager perceives him or her and the group of employees is getting along together.

\subsection{Gaps in the Literature}

A thorough but synoptic review of empirical works on leadership styles and employee performance established a condescending nod to a positive relationship between the former and the latter. Notwithstanding, the existence of variances in previous findings evokes reflections on whether such empirical evidence is globally applicable to all work contexts. More so, there is a paucity of scientific knowledge on the status quo in Cameroon thus limiting a fair comprehension of the subject. The foregoing situation therefore is a clarion call for more research on the subject of leadership styles and employee performance in Cameroon so as to align, contrast or rewrite existing scholarly positions when it comes to leadership. Taking this into consideration this study sought to bridge this gap in the literature which influences organizational performance in Cameroon.

\section{Methodology}

\subsection{Research Design}

In this study, the survey research design has been used with focus on questionnaires adopted for primary data collection. Survey research was used to gain background information, clarify problems and hypothesis as well as to establish research priorities.

\subsection{Population}

The population of the study was made up of 150 (120 full-time and 30 part-time) workers at SVMC. The full-time employees were those officially recruited by the SVMC and had received a contract of employment specifying their functions and general terms of reference. They are also always available at work on a daily basis and have worked for more than two years. They also have a full understanding of the leadership situation in St. Veronica. The part time employees were contracted on hourly basis and had no binding contract of agreement specifying their terms of reference. They only came to work at spe-

cific hours and most of them have schedules that span not more than three months. They have little or no experience about the leadership situation in St. 
Veronica.

\subsection{Sample and Sampling Technique}

A simple random sampling technique was used and 100 employees were selected for this study using the Krejcie and Morgan (1970) table specifying the sample from a given population in a tabular form.

\subsection{Instrument for Data Collection}

The questionnaire was designed by the researcher and used as the main instrument for data collection because it provided an efficient way of collecting responses from a representative sample. The questionnaire provided the current opinions and impressions of the business operation in relation to the topic under study and attempted to standardize the questions answered by respondents. The questionnaire was weighted on a five-point Likert scale (strongly agree, agree, neutral, disagree and strongly disagree) and constituted 32 items in total.

\subsection{Validation of the Instrument}

The research instrument was tested for internal consistency through the use of composite reliability, convergent and discriminant analyses which are indicators of construct validity ensures the measured items were a true representation on the latent constructs and to determine the extent to which the constructs discriminated between themselves.

Table 1 shows the composite reliability method that was used in estimating reliability which is a measure of internal consistency and evaluates the extent to which the measured variables consistently represent their latent constructs. The composite reliability for the latent constructs were $\mathrm{EL}=0.95, \mathrm{TL}=0.89, \mathrm{DL}=$ 0.95 and $\mathrm{AL}=0.77$. All the estimates were above the criterion of 0.6 which is an indication of high internal consistency of the measured variables with the latent constructs.

The convergent validity is a measure of construct validity indicating the degree to which measured variables come together in determining their underlying factor structure. The estimates for the latent constructs using average variance extracted were; $\mathrm{EL}=0.74, \mathrm{TL}=0.74, \mathrm{DL}=0.78$ and $\mathrm{AL}=0.52$ which were all greater than the set criterion of 0.50 , indicating high convergence of the measured variables to the constructs.

In Table 2, the discriminant validity indicates the degree of variation between latent constructs and is a measure of construct validity. The discriminant values in the leading diagonal are expected to be more than the latent variables correlation. The discriminant values for the latent constructs in the leading diagonals are: $\mathrm{EL}=0.86, \mathrm{TL}=0.86, \mathrm{DL}=0.88$ and $\mathrm{AL}=0.72$ (all in red on the table) which are all greater than all other pairs of correlations in the matrix. This therefore indicates that the latent constructs strongly discriminate between each other. 
Table 1. Composite reliability and convergent validity.

\begin{tabular}{ccccc}
\hline Latent constructs & $\begin{array}{c}\text { Ethical Leadership } \\
(\mathrm{EL})\end{array}$ & $\begin{array}{c}\text { Transformational } \\
\text { Leadership (TL) }\end{array}$ & $\begin{array}{c}\text { Democratic } \\
\text { Leadership (DL) }\end{array}$ & $\begin{array}{c}\text { Authoritative } \\
\text { Leadership (AL) }\end{array}$ \\
\hline CR & 0.95 & 0.89 & 0.95 & 0.77 \\
AVE & 0.74 & 0.74 & 0.78 & 0.52 \\
\hline
\end{tabular}

$\mathrm{CR}=$ Composite reliability, $\mathrm{AVE}=$ Average variance extracted.

Table 2. Discriminant validity.

\begin{tabular}{ccccc}
\hline Latent variables & $\begin{array}{c}\text { Ethical } \\
\text { Leadership }\end{array}$ & $\begin{array}{c}\text { Transformational } \\
\text { Leadership }\end{array}$ & $\begin{array}{c}\text { Democratic } \\
\text { Leadership }\end{array}$ & $\begin{array}{c}\text { Authoritative } \\
\text { Leadership }\end{array}$ \\
\hline Ethical Leadership (EL) & 0.86 & & & \\
Transformational & 0.61 & 0.86 & 0.88 & \\
Leadership (TP) & 0.52 & 0.71 & 0.72 \\
$\begin{array}{c}\text { Democratic } \\
\text { Leadership (DL) } \\
\text { Authoritative } \\
\text { Leadership (AL) }\end{array}$ & 0.39 & 0.48 & 0.51 & 0.72 \\
\hline
\end{tabular}

Discriminant values are read in the leading diagonal only.

\subsection{Method of Data Analysis}

Data collected from the questionnaires were analyzed using Statistical Package of Social Science (SPSS) version 26.0. Measures of central tendency (mean) and dispersion (standard deviation) were used for descriptive statistics. The hypotheses were tested at the 0.05 level of significance using multiple regression technique and independent sample t-test.

\subsection{Verification of Research Hypotheses}

$\mathrm{Ho}_{1}$ : The leadership style predominantly used by managers of SVMC has no significant effect on employees' performance

Multiple linear regression was used to establish the leadership style predominantly used by managers of SVMC and its effect on employees' performance. As seen in Table 3, the $\mathrm{r}$ square parameter estimate indicates that $62.9 \%$ of the variance in employee performance was accounted for by transformational leadership, democratic leadership, ethical leadership and authoritative leadership. The residual estimate of $37.1 \%$ could be accounted for by other factors. The regression ANOVA shows that employee performance has a significant $(\mathrm{F}(4,80)=$ $17.81, p<0.01)$ effect on the four leadership styles.

Table 3 also indicates that SVMC predominantly used three of the four leadership styles, with Democratic leadership being the most significantly $(\mathrm{B}=0.59$, $\mathrm{SE}=0.19, \mathrm{t}=2.71, p=0.001)$ used, having a positive effect on employee performance. Closely followed was the transformational leadership which has a significant $(\mathrm{B}=0.44, \mathrm{SE}=0.11, \mathrm{t}=2.51, p=0.004)$ positive effect on employee performance. Ethical consideration was the third most predominant leadership style 
used in SVMC with a significant $(\mathrm{B}=0.35, \mathrm{SE}=0.14, \mathrm{t}=1.69, p=0.039)$ positive effect on employees' performance. Finally, the authoritative leadership style was insignificantly $(\mathrm{B}=-0.20, \mathrm{SE}=0.20, \mathrm{t}=-0.94, p=0.47)$ related to employees' performance and was seldom used by managers of SVMC.

$\mathrm{Ho}_{2}$ : There is no significant difference between gender and leadership styles in SVMC

As seen in Table 4, an independent sample $t$ test was used to establish the difference between gender and leadership styles. The parameter estimates of transformational leadership $\left(\mathrm{t}_{(83)}=2.51, p=0.06\right)$ did not differ significantly for male $(\bar{X}=15.35, \mathrm{SD}=2.38)$ and female $(\bar{X}=14.09, \mathrm{SD}=1.72)$ managers. There is no significant $\left(\mathrm{t}_{(83)}=2.71, p=0.89\right)$ mean difference between the parameters of democratic leadership for male $(\bar{X}=18.01, \mathrm{SD}=2.49)$ and female $(\bar{X}=17.67$, $\mathrm{SD}=2.01)$ managers. However, Female managers $(\bar{X}=13.27, \mathrm{SD}=1.90)$ portrayed significantly $\left(\mathrm{t}_{(83)}=1.69, p=0.04\right)$ better ethical leadership behaviors than their male counterparts $(\bar{X}=5.18, \mathrm{SD}=1.63)$. Finally, male managers $(\bar{X}=$ $10.93, \mathrm{SD}=1.85)$ exhibited significantly $\left(\mathrm{t}_{(83)}=-0.92, p=0.002\right)$ higher authoritative leadership traits than female managers $(\bar{X}=4.71, \mathrm{SD}=1.47)$. Therefore transformational and democratic leadership styles were gender invariant while ethical and authoritative leadership styles varied significantly with gender of the manager.

Table 3. Leadership style predominantly used by managers of SVMC.

\begin{tabular}{|c|c|c|c|c|c|c|}
\hline Variable & $\mathrm{B}$ & SE & $\mathrm{t}$ & $p$ & $\mathrm{~F}(\mathrm{df})$ & $\mathrm{r}^{2}$ \\
\hline Transformational leadership & 0.438 & 0.108 & 2.512 & $0.004^{*}$ & & \\
\hline Democratic leadership & 0.586 & 0.188 & 2.714 & $0.000^{\star *}$ & & \\
\hline Ethical leadership & 0.353 & 0.141 & 1.693 & $0.039^{*}$ & $17.81^{\star *}(4,80)$ & 0.692 \\
\hline Authoritative leadership & -0.198 & 0.196 & -0.942 & 0.472 & & \\
\hline Constant & 16.162 & 3.817 & 1.84 & 0.000 & & \\
\hline
\end{tabular}

${ }^{\star} p<0.5,{ }^{*} p<0.01, \mathrm{~B}=$ Standardized regression coefficient, $\mathrm{SE}=$ Standard error, $p=$ significance.

Table 4. Gender and leadership styles in SVMC.

\begin{tabular}{|c|c|c|c|c|c|c|}
\hline Variable & Gender & $\bar{X}$ & $\mathrm{SD}$ & $\mathrm{t}$ & df & $p$ \\
\hline \multirow[b]{2}{*}{ Transformational leadership } & M & 15.35 & 2.38 & \multirow[b]{2}{*}{2.512} & \multirow[b]{2}{*}{83} & \multirow[b]{2}{*}{0.064} \\
\hline & & & & & & \\
\hline \multirow{3}{*}{ Democratic leadership } & M & 18.01 & 2.49 & \multirow{3}{*}{2.714} & \multirow{3}{*}{83} & \multirow{3}{*}{0.89} \\
\hline & & & & & & \\
\hline & $\mathrm{F}$ & 17.68 & 2.01 & & & \\
\hline \multirow{3}{*}{ Ethical leadership } & M & 5.18 & 1.63 & \multirow{3}{*}{1.693} & \multirow{3}{*}{83} & \multirow{3}{*}{$0.039^{*}$} \\
\hline & & & & & & \\
\hline & $\mathrm{F}$ & 13.27 & 1.90 & & & \\
\hline \multirow{3}{*}{ Authoritative leadership } & M & 10.93 & 1.85 & \multirow{3}{*}{-0.942} & \multirow{3}{*}{83} & \multirow{3}{*}{$0.002^{\star *}$} \\
\hline & & & & & & \\
\hline & $\mathrm{F}$ & 4.71 & 1.47 & & & \\
\hline
\end{tabular}

${ }^{\star} p<0.5,{ }^{* *} p<0.01, \bar{X}=$ mean, $\mathrm{SD}=$ standard deviation, $\mathrm{M}=$ male, $\mathrm{F}=$ female, $p=$ significance. 
$\mathrm{Ho}_{3}$ : There is no significant relationship between the estimates of the linear regression model on leadership styles and employee performance

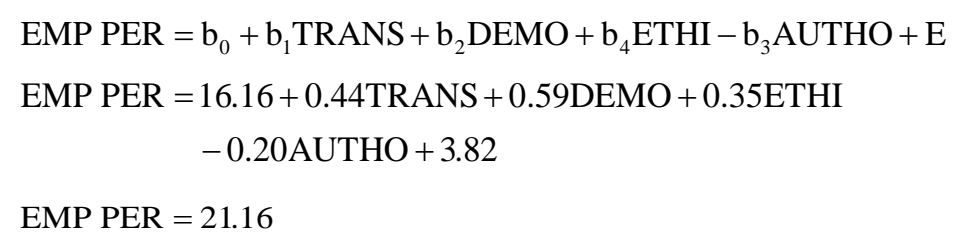

Table 5 reports that a unit increase in the leadership styles (transformational, democratic, ethical) will improve employee performance by $21.16 \%$ and a unit decrease in authoritative leadership increases employee performance by $21.16 \%$. Therefore, there is a significant positive relationship between the estimates of the linear regression model and employee performance expect for authoritative leadership with a negative insignificant estimate.

\section{Discussion of Findings}

\subsection{The Specific Leadership Behaviours Exhibited by Managers in Enhancing Employee Performance in the St. Veronica Medical Center}

This study encompassed four leadership styles: ethical leadership, authoritative leadership, transformational leadership and the democratic leadership styles. From the results obtained in chapter four, it was realized that respondents had varied views pertaining to the different leadership styles exhibited in their institution.

With respect to ethical leadership styles, the results showed that supervisors in this institution exhibit all the leadership styles except authoritative which was fairly used. The administrators practiced ethical leadership by encouraging employees to use unified procedures and techniques in carrying out tasks. As an ethical gesture in leadership, supervisors are friendly, approachable and treat employees with fairness and do not discriminate but rather encourage fair promotion. It was also established that managers and supervisors in the SVMC portray some high moral standards by ensuring that meritocracy is promoted in the institution wherein credits are given to whom it is due. As such it was commended that leaders of the SVMC portray ethical conducts in their leadership through their transparency, friendliness, fairness; trust worthiness and confidentiality.

Table 5. Linear regression model on leadership styles.

\begin{tabular}{ccccc}
\hline Variable & $\mathrm{B}$ & $\mathrm{SE}$ & $\mathrm{t}$ & $p$ \\
\hline Transformational leadership & 0.438 & 0.108 & 2.512 & $0.004^{*}$ \\
Democratic leadership & 0.586 & 0.188 & 2.714 & $0.000^{* *}$ \\
Ethical leadership & 0.353 & 0.141 & 1.693 & $0.039^{*}$ \\
Authoritative leadership & -0.198 & 0.196 & -0.942 & 0.472 \\
Constant & 16.162 & 3.817 & 1.84 & 0.000 \\
\hline
\end{tabular}

${ }^{\star} p<0.5,{ }^{* *} p<0.01, \mathrm{~B}=$ Standardized regression coefficient, $\mathrm{SE}=$ Standard error. 
This confirms the findings of Brown et al. (2005) who suggested that the combination of integrity, ethical standards, and fair treatment of employees are the cornerstones of ethical leadership. Also, Oates and Dalmau (2013) expounded that ethical leadership is about doing what is right for the long term benefits of all stakeholders. It is about balancing the organization's short term goals and longer term aspirations in a way that achieve positive results for all those who could be affected by the organization and the decisions of its leaders.

With respect to authoritative leadership styles, the study portrayed that leaders in the SVMC are not authoritative because majority of the respondents held the view that performances in the institution are not assessed by supervisors alone, supervisors do not dictate what should be done and how it should be done in their institution. Despite this, some authoritative attributes were evident in that managers of the institution were confirmed to be solely responsible for the designing of the rules and regulations governing the institution. This is in tandem with Akor (2014) that an authoritative leader takes the decisions and expects subordinates to carry them out without question.

From the analysis also, it was discovered that transformational leadership was an obvious leadership style exhibited by leaders in the SVMC. They exhibited "ideal" levels of transformational leadership behaviors such as inspiring a shared vision, talking optimistically, encouraging creativity and placing much importance in coaching or training. Findings indicated that supervisors in this institution help employees to develop their strength, enabled them to adapt to new work environment and even encouraged them to be optimistic about the future by instilling in them new mindsets.

This is in line with Storey and Salaman (2004) who reported that transformational leadership is composed of four dimensions; ideal influence, inspirational motivation, intellectual stimulation and individualized consideration. Hoy and Miskel (2008) equally viewed transformational leadership behavior as one characterized by individualized consideration, inspiration, intellectual stimulation and charisma; that provide high-performance and active leadership. Hence, the above results are in line with previous research (Storey \& Salaman, 2004; Hoy \& Miskel, 2008) because leaders in SVMC have intellectual stimulation and charisma which enables them to encourage employees to develop their strength and build new work ethics that promote good work environment.

Lastly, the study sought to examine employees' opinions on the evidence of democratic leadership in their institution. Findings revealed that supervisors in this SVMC have democratic leadership characters. They encourage employees to take initiatives at work, encourage delegation and division of labour, consult their employees during decision making, involve them in performance appraisals in their department and encourage team work.

Tandoh (2011) support these findings as they posited that a democratic leader would characteristically lay the problem before his or her subordinates and invite discussion. The leader's role is that of conference leader, or chair, rather 
than that of decision taker. He or she will allow the decision to emerge out of the process of group discussion, instead of imposing it on the group as its boss (Tandoh, 2011).

\subsection{Leadership Behaviours That Affect the Performance of Employees}

Findings revealed that employees believed that because of high democratic, transformational and ethical behaviours in their institution they are fairly treated because they receive regular job performance feedbacks and always endeavour to realize the tasks assigned to them given the conducive work environment. Their leaders however very much appreciate their efforts as workers and give them opportunities to advance in their career thus enhancing their productivity. Mwita (2000) propounded that employee performance is the key multi character factor intended to attain outcomes which has a major connection with planned objectives of the organization. The above findings are in accordance with those of Detert et al. (2000) who discovered that an efficient leadership style helps employees in discovering and polishing their contributions to the success of the organization.

Mayer et al. (2009) also found positive effects of executive ethical leadership cascade to lower level employees through the ethical leadership practiced by supervisors. This was further confirmed by Walumbwa and Schaubroeck (2009) that the perceptions of ethical leadership were related to increased employee voice via their influences on heightened psychological safety.

\subsection{Conclusion}

This research unmasked an insufficiency of relevant literature in the area of leadership in Cameroon more so in the context of private Small and Medium Size Enterprises such as St. Veronica Medical Center. A bulk of existing literature especially those exploited in this paper is culled from western research. Based on the findings of this study, leadership behavior is quite essential to the performance of employees in all sectors of activities. Leadership is a process through which an individual influences a group of people to attain common goals. In this study it has been established that supervisors and managers exhibit mostly the transformational leadership styles through which they assist employees to develop their strength, enable them to adapt to new work environment and even encourage them to be optimistic about the future by instilling in them new mindsets.

This has resulted into increase employees' performance since they perceive fairness in the workplace; receive regular job performance feedbacks which make the work environment interactive and enable them to realize the tasks assigned to them. Democratic leadership was the most significantly $(\mathrm{B}=0.59, \mathrm{SE}=0.19, \mathrm{t}$ $=2.71, p=0.001)$ used, having a positive effect on employee performance. Closely followed was the transformational leadership which has a significant (B 
$=0.44, \mathrm{SE}=0.11, \mathrm{t}=2.51, p=0.004)$ positive effect on employee performance. Hence, it was concluded that for employees' performances to be enhanced through leadership, managers should build trust in their staff by giving them responsibilities and allowing them to execute tasks without cohesions, and inspire staff through continuous encouragement/motivation (praise, awards, prizes, recognition) by acknowledging excellent job done, as well as making them to be a part of the institutions shared vision (involving them in decision making and seeking their opinion on best strategies to improve on the organization). While the place of leadership and employee performance in literature has been fairly attempted in this study with the foregoing results, calls are equally been made for more research to establish a fair comprehension of the subject within the context of Cameroon.

\subsection{Limitations of the Study}

The present study sought to ascertain the place of leadership styles on employee performance in Cameroon; however data acquisition and the related findings are limited to the St. Veronica Medical Center in Buea of the Southwest Region of Cameroon. Thus much is yet to be known about the prevailing situation in other organizations across the country.

Also, the present study methodologically leaned on a quantitative approach and applied a survey as its research design. As such data were collected through questionnaires which left the respondents with inadequate response options. It is possible that much information could have been solicited through a qualitative approach with multiple instruments such as interviews and focus group discussions.

Finally, a larger portion of the literature and empirical sources exploited in this paper are culled from western settings as such it may be difficult to directly understand the status quo in Cameroon which is a less developed setting via the lenses of Euro-American knowledge systems.

\section{Conflicts of Interest}

The author declares no conflicts of interest regarding the publication of this paper.

\section{References}

Akor, P. U. (2014). Influence of Autocratic Leadership Style on the Job Performance of Academic Librarians in Benue State. Journal of Educational and Social Research, 4, 148-152. https://doi.org/10.5901/jesr.2014.v4n7p148

Amos, T., Ristow, A., \& Ristow, L. (2004). Human Resource Management (2nd ed.). Lansdowne: Juta.

Armstrong, M. (2004). Human Resource Management Theory and Practice. London: Bath Press Ltd.

Armstrong, M., \& Baron, A. (1998). Performance Management Handbook. London: IPM.

Bartlett, C. A., \& Ghoshal, S. (1995). Global Strategic Management: Impact on the New 
Frontiers of Strategy Research. Harvard Business Review, 73, 86-96.

Bass, B. M. (1985). Leadership and Performance beyond Expectations. New York: Free Press.

Bass, B. M. (1997). Does the Transactional-Transformational Leadership Paradigm Transcend Organizational and National Boundaries? American Psychologist, 52, 130-139. https://doi.org/10.1037/0003-066X.52.2.130

Bello, S. M. (2012). Impact of Ethical Leadership on Employee Job Performance. International Journal of Business and Social Science, 3, 228-236.

Berson, Y., \& Avolio, B. J. (2004). Transformational Leadership and the Dissemination of Organizational Goals: A Case Study of a Telecommunication Firm. The Leadership Quarterly, 15, 625-664. https://doi.org/10.1016/j.leaqua.2004.07.003

Brown, M. E., \& Treviño, L. K. (2006). Ethical Leadership: A Review and Future Directions. The Leadership Quarterly, 17, 595-616. https://doi.org/10.1016/j.leaqua.2006.10.004

Brown, M. E., Treviño, K. L., \& Harrison, D. (2005). Ethical Leadership: A Social Learning Perspective for Construct Development and Testing. Organizational Behaviour and Human Decision Processes, 97, 117-134. https://doi.org/10.1016/j.obhdp.2005.03.002

Burns, J. M. (1978). Leadership. New York: Harper \& Row.

Cummings, L. L., \& Schwab, D. P. (1973). Performance in Organizations: Determinants \& Appraisal. Glenview, IL: Scott, Foresman.

Detert, J. R., Schroeder, R. G., \& Mauriel, J. J. (2000). A Framework for Linking Culture and Improvement Initiatives in Organizations. Academy of Management Review, 25, 850-863. https://doi.org/10.5465/amr.2000.3707740

Dorasamy, N. (2010). The Impact of the Global Crisis on Ethical Leadership: A Case Study of the South African Public Sector. African Journal of Business, 4, 2087-2096.

Fiedler, F. (1967). A Theory of Leadership Effectiveness. New York: McGraw-Hill.

Fiedler, F. E., \& House, R. J. (1988). Leadership Theory and Research, a Report of Progress. International Review of Industrial and Organizational Psychology, 19, 73-91.

Furkan, B., Kara, E., Tascan, E., \& Avsalli, H. (2010). The Effects of Leadership on Job Satisfaction (Visionary Leadership, Transformational Leadership, Transactional Leadership). 3rd International Symposium on Sustainable Development, Sarajevo, 2012 220-226.

Gadot, E. V. (2006). Compulsory Citizenship Behaviour: Theorizing Some Dark Sides of the Good Soldier Syndrome in Organizations. Journal for the Theory of Social Behaviour, 36, 77-93. https://doi.org/10.1111/j.1468-5914.2006.00297.x

Givens, R. J. (2008). Transformational Leadership: The Impact on Organizational and Personal Outcomes. Emerging Leadership Journeys, 1, 4-24.

Grant, A. M., Christianson, M. K., \& Price, R. H. (2007). Happiness, Health, or Relationships? Managerial Practices and Employee Wellbeing Trade-Offs. Academy of Management Perspectives, 21, 51-63. https://doi.org/10.5465/amp.2007.26421238

Hoy, W. K., \& Miskel, C. G. (2008). Educational Administration Theory, Research, and Practice (8th ed.). New York: McGraw-Hill.

Jones, G. R., \& George, J. M. (2004). Essentials of Contemporary Management. Boston, MA: McGraw Hill Companies, Inc.

Judge, T. A., \& Piccolo, R. (2004). Transformational and Transactional Leadership: A Meta-Analytic Test of Their Relative Validity. Journal of Applied Psychology, 5, 755-768. https://doi.org/10.1037/0021-9010.89.5.755 
Kalshoven, K., Den Hartog, D. N., \& De Hoogh, A. H. B. (2011). Ethical Leader Behavior and Big Five Factors of Personality. Journal of Business Ethics, 100, 349-366. https://doi.org/10.1007/s10551-010-0685-9

Kodish, S. (2006). The Paradoxes of Leadership: The Contribution of Aristotle. Leadership, 2, 451-468. https://doi.org/10.1177/1742715006069175

Kotter, J. P. (1988). The Leadership Factor. New York: The Free Press.

Krejcie, R. V., \& Morgan, D. W. (1970). Determining Sample Size for Research Activities. Educational and Psychological Measurement, 30, 607-610. https://doi.org/10.1177/001316447003000308

Krishnan, V. R. (2012). Transformational Leadership and Personal Outcomes: Empowerment as Mediator. Leadership \& Organization Development Journal, 33, 550-563. https://doi.org/10.1108/01437731211253019

Maccoby, M. (2000). Narcissistic Leaders: The Incredible Pros, the Inevitable Cons. Harvard Business Review, 78, 68-77.

Maritz, D. (1995). Leadership and Mobilizing Potential, Human Resource Management. International Journal of Global Business, 10, 8-16.

Mayer, D., Kuenzi, M., Greenbaum, M., Bardes, R., \& Salvador, M. R. (2009). How Low Does Ethical Leadership Flow? Test of a Trickle-Down Model. Organizational Behaviour and Human Decision Processes, 108, 1-13. https://doi.org/10.1016/j.obhdp.2008.04.002

McGregor, D. (1960). The Human Side of Enterprise. New York: McGraw-Hill Book Co.

Mintzberg, H. (2010). Managing on Three Planes. Leader to Leader, 57, 29-33. https://doi.org/10.1002/ltl.425

Mullins, L. (1999). Management and Organizational Behaviour. London: Pitman Publishing.

Mwita, J. I. (2000). Performance Management Model, a System-Based Approach to Quality. The International Journal of Public Sector Management, 13, 19-37. https://doi.org/10.1108/09513550010334461

Northouse, P. G. (2010). Leadership, Theory and Practice (5th ed.). Thousand Oaks, CA: Sage.

Northouse, P. G. (2016). Leadership, Theory and Practice (7th ed.). Thousand Oaks, CA: Sage Publications Inc.

Oates, V., \& Dalmau, T. (2013). Ethical Leadership: A Legacy for a Stronger Future. Performance, 5, 20-27.

Ogbonna, C., \& Harris, L. (2000). Leadership Style, Organizational Culture and Performance: Empirical Evidence from UK Companies. The International Journal of Human Resource, 11, 766-788. https://doi.org/10.1080/09585190050075114

Piccolo, R. F., Greenbaum, R., Den Hartog, D. N., \& Folger, R. (2010). The Relationship between Ethical Leadership and Core Job Characteristics. Journal of Organizational Behavior, 31, 259-278. https://doi.org/10.1002/job.627

Ristow, A., Amos, T., \& Staude, G. (1999). Transformational Leadership and Organizational Effectiveness in the Administration of Cricket in South Africa. South African Journal of Business Management, 30, a749. https://doi.org/10.4102/sajbm.v30i1.749

Storey, J., \& Salaman, G. (2004). Managers of Innovation: Insights into Making Innovation Happen. Oxford: Blackwell.

Suri, S. (2016). Influence of Leadership Style on Employee Motivation and Performance. International Journal of Research in Management, 5, 65-71. 
Swanepoel, B., Erasmus, B., Van Wyk, M., \& Schenk, H. (2000). South African Human Resource Management: Theory and Practice. Kenwyn: Juta and Co. Ltd.

Tandoh, V. (2011). Effect of Leadership Behaviours on Employee Performance in Guinness Ghana Breweries Limited. Ashanti: Kwame Nkrumah University of Science and Technology.

Temple, B. (2002). Avoid Downsizing Disasters: Empower Your Employees. San Diego Business Journal, 23, 22-45.

Treviño, L. K., \& Brown, M. E. (2004). Managing to Be Ethical: Debunking Five Business Ethics Myths. IEEE Engineering Management Review, 32, 39-52. https://doi.org/10.1109/EMR.2004.25135

Wall, B., Solum, R. S., \& Sobol, M. R. (1992). The Visionary Leader. Rocklin, CA: Prima Publishing.

Walumbwa, F. O., \& Schaubroeck, J. (2009). Leader Personality Traits and Employee Voice Behavior: Mediating Roles of Ethical Leadership and Work Group Psychological Safety. Journal of Applied Psychology, 94, 1275-1286. https://doi.org/10.1037/a0015848

Wang, H., Law, K., Hackett, R., Duanxu, W., \& Chen, Z. X. (2005). Leader-Member Exchange as a Mediator of the Relationship between Transformational Leadership and Followers' Performance and Organizational Citizenship Behavior. The Academy of Management Journal, 48. https://doi.org/10.5465/amj.2005.17407908

Yukl, G. (2006). Leadership in organizations (6th ed.). Upper Saddle River, NJ: Prentice Hall. 